\title{
Multilingualism in transformative spaces: contact and conviviality
}

\author{
Quentin Emmanuel Williams and Christopher Stroud
}

\begin{abstract}
South Africa is a highly mobile country characterized by historical displacements and contemporary mobilities, both social and demographic. Getting to grips with diversity, dislocation, relocation and anomie, as well as pursuing aspirations of mobility, is part of people's daily experience that often takes place on the margins of conventional politics. A politics of conviviality is one such form of politics of the popular that emerges in contexts of rapid change, diversity, mobility, and the negotiation and mediation of complex affiliations and attachments. The questions in focus for this paper thus pertain to how forms of talk, born out of displacement, anomie and contact in the superdiverse contexts of South Africa, allow for the articulation of life-styles and aspirations that break with the historical faultlines of social and racial oppression. We first expand upon the idea of (marginal) linguistic practices as powerful mediations of political voice and agency, an idea that can be captured in the notion of linguistic citizenship, the rhetorical foundation of a politics of conviviality. We then move on to analyze the workings of linguistic citizenship in the multilingual practices of two distinct manifestations of popular culture, namely hip hop and a performance by a stand-up comedian in Mzoli's meat market in Gugulethu, Cape Town. The paper concludes with a general discussion on the implications for politics of multilingualism and language policy.
\end{abstract}

\section{Introduction}

In a highly mobile new South Africa, characterized by historical displacements and contemporary mobilities, both social and demographic, a large part of people's daily life involves getting to grips with diversity, dislocation, relocation and anomie, while at the same time attempting to pursue aspirations of mobility in a context of post-racial inequity. For the most part, this takes place outside of the institutional forms and against the grain of, conventional political forums. Arnfred notes attempts by women's movements in the African context generally to base "a new democratic culture [...] on bottom-up participation and on social movements outside the parliamentary structures” (Arnfred and Utas 2007: 8), and Chipkin (2007) argues for South Africa specifically, that citizenship should be defined by "feelings of friendship and solidarity reproduced through interactions of democratic practice" and not by territorial limits or ethnic and racial or cultural indices. One question in focus for this paper thus pertains to how forms of talk, born out of displacement, anomie and contact in the superdiverse contexts of South Africa, allow for the articulation of life-styles and aspirations that 
"cross historical faultlines of ethnicity, class, religion, political affiliation, sexuality and gender" (Fanshawe and Sriskandarajah 2010)?

Attending to the role of language in 'bridging divides, repairing inequalities and redistribution of power' (Shohamy 2006: 133), poses a host of challenges for contemporary language policy (Shohamy 2006; Agnihotri 2007: 80). The conceptual frameworks through which policy making and implementation are conventionally understood (Kennett 2008: 3) can only with difficulty translate values such as care, empathy, and respect for diversity (Coste and Simon 2009: 175; Sennett 2005), or a 'civility towards diversity' (Lofland 1998) into a language policy for democracy? Thus, a central question is how can the contingent diversity of local multilingual practices in everyday convivial interactions be made to speak to the reconfiguration of public spaces, so as to allow for a broader based democratic involvement?

In this paper, we attempt to open up one inroad to these questions by first expanding upon the idea of (marginal) linguistic practices as powerful mediations of political (convivial) voice and agency, an idea that can be captured in the notion of linguistic citizenship, as a lens on the quotidian accomplishment of conviviality. A key site for the working through of convivial citizenship is the local, a prominent arena of transnational and transformational encounters, where diversity is played out on a daily basis. It is at the level of the local that groups and individuals will encounter each other, engage around mutual concerns of consensus or contention, and move towards solutions to possible intractable conditions of co-existence and 'harmony'. Here, we take two performances of and in the local as the point of departure for the analysis, namely Hip-Hop and a performance by a stand-up comedian in Mzoli's meat market in Gugulethu, Cape Town. The performers script everyday encounters that illustrate how abstract rights and obligations are realized in "the everyday lived experiences and local negotiations of difference on microcultures of space" through "distinctive individual and interpersonal experiences.” (Amin 2002: 967). We conclude the paper by drawing out some of the implications of the analysis for language policy to suggest that language policy research should consider more seriously the momentary and fluid nature of a variety of linguistic forms that are reflective of scaled linguistic productions of the everyday.

\section{Linguistic citizenship: language for a politics of conviviality}

Conventional approaches to linguistically mediated diversity have tended to build on a liberal tradition of recognition that affirms the rights of speakers to have their languages recognized on an equal basis in public arenas. This paradigm of linguistic human rights has been found lacking in many respects. Stroud (1998, 2001, 2009) and Stroud and Heugh (2004) have argued that such policies tend to promote selective agency, ignore the material and economic constraints in the implementation of rights, and to reproduce understandings of language that continue to disadvantage non-standard speakers. Importantly, LHR based policies, presuppose a mosaic view of linguistic and social order, and are therefore unable to deal with the quotidian mix and mesh of everyday politics in rapidly emerging, transnational and cosmopolitan encounters in speech communities that are increasingly complex, stratified and hybrid. Interestingly, it is precisely the ordinariness of everyday complex multilingual 
interactions that brings out the inadequacies of much conventional language policies, to the extent they remain geared to 'monoglot' management of 'disturbing' diversity.

A useful notion when seeking to understand how displaced identities in flux find productive points of contact and exchange is conviviality, which is the stuff of Amin's (2002) 'sites of habitual engagement' (cf. Wessendorf 2010). Although convivial relationships are typically everyday, mundane encounters, contexts of rapid change, and upheaval, diversity and mobility, afford particularly rich insights into how complex affiliations and attachments are negotiated, mediated and contested. Gilroy (2004: xi) defines conviviality as "processes of cohabitation and interaction that have made multiculturalism an ordinary feature of social life" and Blommaert (forthcoming: 102) characterizes it as "the attitude that enables people to accept different trajectories of life and different ways of going about things within the same space". Similar thoughts are captured in the idea of 'cosmopolitanism from below' (Werbner 1999), 'corner-shop cosmopolitanism or banal cosmopolitanism' (Noble 2009: 49) or 'pragmatic-beingtogether' (Noble 2009), notions that all seek to understand the interpersonal mechanics behind, what Noble (2009) has called, 'unpanicked multiculturalism'.

It would be wrong to see conviviality as only referring to joyous and harmonious coexistence, however. Conviviality can be the outcome of tense interactions and negotiated difference. Karner and Parker (2011), for example, take issue with the tendency in sociological thought to see communities exclusively in terms of a politics of exclusions and alliances and as exhibiting 'community cohesion' or its absence. They point instead to the politics of ambivalence defined by "complex social realities defined by a series of ambivalences" (2011: 355), claiming that people "can act together without the compulsion to be the same" (Sennett 1974: 255). ${ }^{1}$

Conviviality in these senses is key to a politics of the everyday. Illich complains of how "at present people tend to relinquish the task of envisaging to a professional elite" and uses the term conviviality to designate "the autonomous and creative intercourse among persons" (Illich 1973). Yuval-Davis (1999) speaks of transversal politics' where speakers, conscious of their own identity (rootedness) nevertheless attempt to position themselves in the life-world of the Other (shifting). A useful differentiation here is Lofland (1998) distinction between different 'zones of encounter' (Wood and Landry 2007), 'social territories defined by specific relational forms", such as the private sphere, characterized by intimate relationships with family and friends; the parochial sphere of relations between colleagues or compatriots in associational networks, clubs, and other organizations; and the public sphere, the world of the street and other public contexts characterized by a relative degree of formality and estrangement. As the boundaries between these spheres are fluid, relationships typical of the parochial sphere, a prime site for convivial relationships, may spill over into the private and public spheres, and vice versa ${ }^{2}$ (cf. Wessendorf 2010). In another context, that of adult literacy education

\footnotetext{
${ }^{1}$ Taylor (2004: 7) has actually posed the question "whether it is possible for convivial institutions to exist other than by simply creating another power relationship and social orders" that only appear to allow free reign to individual expression. As we will see below in the analysis, these tensions, contradictions and power plays pervade our data.

${ }^{2}$ Although the local (private and parochial) may be convivial, it is however not necessarily consensual. Mouffe (2000) has noted how a democratic politics is a politics of agonism, of contest and conflict rather than a necessary consensus.
} 
in South Africa, Kerfoot (under review) shows how the shifting use of different languages, language varieties, registers, and (multisemiotic) modes of representation encourages the legitimate recontextualization of a message which serves "to promote inter-group dialogue and to reshape existing distinctions between formal and informal speech along with the power relations bound up in them" (Kerfoot, p. 25). Kerfoot concludes that the recoding and resemiotizations in the transport of meanings and understandings allow voices previously silenced to be heard in ways not possible through "normative" language practices.

Thus conviviality takes us beyond institutional dimensions of citizenship and the institutionalized recognition of rights to emphasize 'agency' and citizenship as "a capacity to act in relation' (Osborne and Rose 1999: 758), and a capacity that is not produced or determined by any one social identity or political alignment but in the multiplicity of relations through which civic associations and attachments are woven (Rose 2000).3 The notion of linguistic citizenship provides an inroad into the semiotic practices whereby convivial relationships are created and sustained. 4 This notion puts the emphasis on the ways in which everyday linguistic practices that enhance speaker agency at the level of the local (private and parochial) also contribute to 'acts of citizenship' and a more equitable speaker presence in the official, wider sphere of the public realm. Much local linguistic practice is typically non-standard and marginal, comprising forms that are effervescent, momentary and fleeting (e.g. Stroud 2009). This feature of linguistic citizenship is pertinent to Rose's (2000) notion of 'minor practices of citizen formation' which are

...linked to a politics of the cramped spaces of action on the here and now, of attempts to reshape what is possible in specific spaces of immediate action, which may connect up and destabilise larger circuits of power (Rose 2000, p. 100)

The idea of linguistic citizenship attempts precisely to work with the linguistic mediation of agency in 'cramped spaces', and with the idea that larger circuits of power are mediated through linguistic engagements with the everydayness of the local. Its emphasis on features of (multilingual and multisemiotic) language use on the margins opens up the potential for understanding the rhetorical foundations of radically different types of speaker agency that go 'against the grain' (of a conventional politics of language); it does this by being attuned to the complex semiotic world of styles, stances and identities around which people play out their lives. It is acts of citizenship in this sense that need to inform a new 'politics of civility' (Nayak 2010; Stroud and Jegels 2012).

A key site for such a politics of the everyday is popular culture, which besides popularized music, religion, and sport, also encompasses "the food we eat, the clothing we wear, the people we spend time with, the gossip we share, the roadways we travel, and so forth" (Harrington and Bielby 2001:2). In the South African context,

\footnotetext{
${ }^{3}$ This is similar to what Block (2011: 162) calls "the more banal day-to-day participation in activities that maintain social cohesion such as membership in sports-clubs, trade unions [...] and so on", that is citizenship as practice.

${ }^{4}$ Originally conceptualized as offering a critique of political constructs of language inherent in (affirmative) liberal rights discourses of politics (e.g. Stroud 2001), the concept has subsequently been further refined in a number of studies (e.g. AnsaldoLim, ftc), and developed in different strands of thinking (e.g. Mercado 2008; Coloumbe 2000).
} 
popular culture has been closely connected to the social and political imagination of the country (Wasserman and Jacobs 2003; Kriger and Zegeye 2001; Nuttall and Michael 2000). Speaking of the African context generally, Dolby (2006) argues that "people's everyday engagements with popular culture [...] must be a central component of understanding emergent public spaces and citizenship practices in Africa, present and future" (2006: 34), as it is a site of struggle, "a place for the negotiation of race, gender, nation and other identities and for the play of power" (Dolby 2006:33). Simone (2008) talks of popular culture as a "form of collective endeavour that converts differences of power and legitimacy into forms of calculation beyond the conventional notions of status and hierarchy, in which everyone can participate and benefit without the outcomes being the product of consensus, conciliation or brokered deals" (p. 76). Taylor (2004: 4) cites Victor Turner who argues "that freed from the constraints of daily life and allowed to engage in playful or transgressive behaviour, people are uplifted and experience the camaraderie of "communitas". Thus, politics and performance come together in the creation of a local public that although convivial may not be free of tension and contradiction.

\section{Two performance sites}

In this paper, we explore two instances of convivial linguistic citizenship in popular spaces, namely Hip Hop and Stand-up comedy. Both Hip Hop and Stand-up are performances that comprise "critical sites for the play of linguistic ideologies about types of people, the varieties they are supposed to speak and the indexical varieties associated with these varieties" (Lo and Kim 2012: 258). Performances are akin to media in that that the voices or stereotypes and stances conveyed, although scripted and not necessarily a true depiction of the facts, nevertheless "provide frameworks of interpretation which people orient to in their everyday lives (Lo and Kim 2012: 258). Importantly, performances are key sites for local enactments and depictions of 'citizenship' in that they involve 'audiences' and thus serve to bridge the private and parochial to the 'public'-in these cases, through various forms of (linguistically mediated) transgression. We explore the two contexts from the point of view of one of the processes central to linguistic citizenship, namely stylization (Rampton 2006).5

\section{Stylizing voice in P.O.C's 'Slang 4 Your Ass'}

The rap performance we analyze here is a track transcribed from P.O.C's (Prophets of da City) 1995 album Universal Souljaz, entitled, 'Slang 4 Your Ass', released during the transition years of South Africa into democracy. P.O.C. was one of the first rap groups to become known in the hip-hop scene of Cape Town, and also the first rap groups to sign a recording contract with a major record company. ${ }^{6}$ Their debut album was called Our World (1990) and many others followed, most notably, Age of Truth (1993) and Universal Souljaz (1995). Slang 4 Your Ass is a rap song and a lyrical voyage performed by a rapper who takes his audience and imagined interlocutors on a trip through the

\footnotetext{
${ }^{5}$ Other important notions are resemiotization (Iedema 2001) and enregisterment (Agha, 2003). A number of recent studies have covered similar ground to this paper in tracking how everyday linguistic processes, such as enregisterment contribute to shifting practices of citizenship and agency (cf. e.g. Newell 2009 for Cote d'Ivoire Goebel 2010, for Indonesia; Roth-Gordon, 2000 for Brazilian favelas; Stroud 2009; Kerfoot 2012 for South Africa), and of seeing comedy performances as 'accidental' language planning of register and style formation (cf. Roth-Gordon 2009; Moriarty and Pietika inen 2011). Lo and Kim (2011, 2012) explore how metapragmatic framings of multilingual competencies in performances index different types of citizenship.

${ }^{6}$ Today more and more genres of rap are emerging. Most notable have been recent forms such as 'Zef Rap' and 'Spaza Rap'.
} 
township. What we find in the lyrical performance of Slang 4 Your Ass is a refiguring of the historical township, a nostalgic panorama of township spaces realized through latemodern discourses of diversity carried in multilingual voices, predominantly a mixing of peripheral forms of English with fragments of local languages or varieties such as Kaaps and isiXhosa. This ludic, metalinguistic, rapsody of township life is simultaneously a commentary on the inequality of languages and identities in township spaces.

The performance opens with a typical township greeting between the rapper and two imagined, multilingual interlocutors, who then proceed to rhyme in chorus how they "kick it" (talk) in the township, back home7.

1. Alles in die haak broetjie, tjek 'it ja

Everthing is in order brother, check it yes

2. Solang die ding ruk is dit tzits ounse

As long as its moving along, its ok guys

3. Is mos soe my broe'!

Just like that my brother!

4. Djy wiet dan

You know

5. Phashaz, hola ghanzaan

I'm ok, how are you?

6. Sien djy my broe

You see my brother

7. die bra kick 'n ander flavou' uit my broe'

That brother kicks a different beat my brother

8. Dis mos mal

That's mad

9. Hy kick 'n ande' flavou' uit

He kicks a different beat

10. Hie' kom 'it!

Here it comes!

11. Kick it the way we do it, in the township!

12. Kick it the way we do it, at home!

13. Kick it the way we do it, at home!

Noticeable here is how the groundwork for the subsequent multilingual performance is introduced by the variety of greetings in the format of an encounter. The rapper proceeds to take the audience on a guided tour of the township. This is done through his performing a palette of (marginal township) voices that not only stylize a range of local personae, but that also link these voices indexically to particular actions, places and township trajectories.

1. I'm walking around with a head full of thought

\footnotetext{
${ }^{7}$ Note on Transcription Convention: All translations into English are italicized in the rap lyrics. In the stand-up comedy transcriptions, all the physical mannerisms and imitations are offered in round brackets.
} 
2. Mixting it with my Township Talk

3. Like/

4. hoe issit?

Howzit?

5. is djy alright?

Are you alright?

14. ek is Will

I am Will

15. en tjek

Check it out

16. dialect into the mic

17. djy kry

You see

18. Then I flex it the other way

19. making them wonder what is going on

20. Where could this man be from?

21. Well

22. we get to that later

23. for now what a dala what a ding it ruk

For now I do and I make things happen

24. Giving foreigners the fits

The narrator takes us with him as he walks in the township "with a head full of thought" (line 15), which he mixes with his "Township talk" (line 16). Moving through township spaces requires that he have the linguistic skills to flexibly engage with the varied populations and stylizations of social selves that populate a Cape Flat's township. In this context, one of the notable aspects of these lines is how the narrator links different forms of language to different spaces in the township, and by so doing allows the different voices to performatively transform township space into a socially meaningful place (cf. Stroud and Jegels 2012). We note here how agency thus extends beyond language proper to also encompass a material semiotics, such as linguistic landscapes that are no less central to semiotic performances of identity and agency.

As he greets others in various forms of 'township talk', using a number of local forms to acknowledge language practices typical of the Township, he presents himself through the eyes and voices of others as not only an accomplished performer, who can use different languages and "dialect into the mic" to "flex it the other way", but significantly, as somebody who can only with difficulty be slotted into any single essentialist social or local identity ('They wonder where this man is from'). We understand from the rapper that his is an identity in 'becoming' that may be revealed in due course. Just as significantly, we note in this context an explicit challenge on behalf of the rapper to, what could be perceived to be, the censorious search for such a categorical identity in 'giving the foreigners the fits' through using township slang in the stylization of multiple selves and complexities of place. In line 29, for instance, the form 'dala' stylizes a particular voice and indexes an agency that is highly marginalized in township life, because it is closely associated with the register of the Number gangs across South Africa. The narrator, however, assures us that voice lyricized here in the form of dala is only for, 
"Giving foreigners the fits". It is part of a transgressive meaning-making (Pennycook 2007: 48) to challenge censorious voices and discourses. This is particularly evident from lines 31 to 36 .

31 'Cause for mee' tzits

Cause I'm the shit

25. Toe slat jou kop with words

I hit you with words

26. And leave you boefana

And leave you thinking

27. making you look like a nwata

Making you look like a fool

28. When I'm on the road skieting kaa'te

When I'm on the road signifying

29. because I got more tricks than ape in a tree

Because I got more tricks than apes in a tree

30. It's just the Township in me

31. to weed and entice to the brothers

32. with the dice and nice guys

The foreigners are being challenged with words in a playful manner to confuse censorious voices that "leave you boefana" (line 33). The township words also leave the foreigners looking like "a nwata" (line 34), someone who is linguistically inept, because those who are multilingual speakers of the township are more playful "on the road skieting karate" (line 35) or have "more tricks than ape in a tree" (line 36). In fact, the expert performance of this lyric has to do with the way marginal voices are indexed through clever use of multiple forms of transgressive and heteroglossic local language. In the rapper's performance, we have a clear 'statement of polycentric normativity', where playful, polycentric creative language is what differentiates the township from normative monoglot hegemony. In fact, the narrator boasts about his playfulness with language: the mixing, blending and bending of local dialects, such as Kaaps, English and isiXhosa, and identifies himself as a township dweller predominantly through the heteroglossia of his language, as he rhymes, "It's just the Township in me/To weed and entice to the brothers/with the dice and nice guys/" (see lines 37 to 39). To the narrator, the township is linguistically diverse, inclusive and non-invasive. It is filled with multivocal encounters (Higgens 2009). In all of these cases, expert use of nonstandard language forms and concerns of local political interest are layered into complex, multilingually mediated stylizations and stances-producing linguistic normativities that go against the grain of the institutional. The skill in performing the lyric is simultaneously a political statement-different voices are brought into conflict rather than consensus in the public space of the performance (cf. Karner and Parker 2011).

The narrator challenges further other censorious and authoritative discourses as he comments on the racial discourses imposed on those living in the township, demonstrating a linkage between 'linguistic protest' and wider political protest. 
6. So Colour me Black

7. like a Gallatie from Malawi

8. Cause I let your mag kreen like pwasa

I let your stomach turn like during fasting

33. When I dala cause I'm the master of kaa'ta

When I act cause I'm the master of signifying

34. So gooi way McGuyver

Do it like McGuyver

35. kap aan driver

Drive Driver

36. Or I'll roll you

37. Like twie dice

Like two dice

38. When I tsais yah

When I go after it yes

39. Like the high cost of living

40. Or the cost of living high

41. Cause it's mos giving my

Because it's giving my

42. Ma and pa se sak ' $n$ helse jak

Mother and father's purse a shake

43. But die liewe is mos soe

Life is like that

44. My broertjie my bra

My brother my brotha

Between lines 84 and 98, he comments on the racial, cultural and economic fault lines (Simone 2008) that are evident in local township spaces. He crosses these fault lines by arguing against authoritative discourse to "Colour me Black/Like a Gallatie from Malawi" (lines 84 and 85). He uses linguistic form such as 'pwasa' (a Malay word used in the Muslim community to refer to period of fasting in Cape Town). Another linguistic form that emerges in the lyric is "tsais" which in this context means to chase (see Williams and Stroud 2010 for a different example). Furthermore, the narrator also comments on the economic situation we find in township life. It is a gamble living in the township, like rolling two dices (lines 90 and 91), because the cost of high living is like the risks taken by township people. Specifically, he refers to how it personally affects him as also a township dweller: it affects "Ma and pa se sak ' $n$ helse jak/But die liewe is mos soe/my broertjie my bra/ (lines 96-98).

From the perspective of linguistic citizenship, the way in which multiple norms are reflectively highlighted in the lyric are one prime means whereby mutual entanglements between the many different stylized and marginalized township Selves are brought into a horizontal association of protest against the panoptic presence of the outsider-the foreigner. We do not find a public space of dialogue so much here as we do a clear demarcation of lines of contention between the multiplicity of the township and the imposition of mainstream normativity (Karner and Parker 2011). We see here an 
instantiation of Ashby's claim that, "Conviviality is achieved for the majority, but only through a process by which non-conviviality is reinforced for the minority" (2004: 1). A key feature behind these faultlines of contention, and the weight carried by the township voice is the promotion of 'inexpert' voices as 'expert' (with the rapper reflecting on language, performing marked language, "kicking it the way we do it in the township”, etc.), where the terms of reference for skilful performance and resonance with an attentive audience are defined by reference to the linguistic practices and metalinguistic arbitrations of the narrator. In fact, it is the very fact of 'transgression' itself, the kicking/more tricks than a monkey, and not just the particular forms of language chosen, that stylizes a political persona. Furthermore, township space is mapped in all its nooks and crannies and unreachable corners through the projection of local voices. All this is accompanied by a clearly emerging and linguistically mediated multiplex identity (or shifting identities) in a politics of becoming throughout the lyric.

\section{Stylizing accents as voices in a meat market}

The context of our analysis of stand-up comic performance is Mzoli's Meat, a popular township restaurant that sells Tshisa-Nyama (Burning-Meat) in Gugulethu, a historically black township on the margins of Cape Town. Gugulethu arose out of the apartheid government's program to rid the city of its black and colored inhabitants, articulated through legislative instruments; such as the Native Urban Areas Act of 1923 and the Group Areas Act of 1950, and subsequently resulting in the massive forced removals to the perimeter of the city that made South Africa infamous.

Mzoli's meat has deep historical roots that can be traced back to the rise of meat markets in black townships across South Africa (Rogerson 1988; Wardrop 2006; Hammett and Jayawardane 2009). Although local, it is a transnational site of consumption attracting tourists from Europe and the States to visit and experience 'authenticity', as well as an emergent middle-class, socially mobile black and coloured South Africans searching for a nostalgic weekend back in the hood. The comedian, Nik Rabinowitz, ${ }^{8}$ whose comic sketch we analyze here says of Mzoli's meat, that,

Well it's an interesting crossed over space because uhm... because of the groups of people that go there; you've got the people from the township, you've got people uhm... you've got the new wealth... the new black wealth, showing off their big cars. Uhm... and it's a place where white, black, coloured people love going. Tourists love going. I don't actually think that many locals go there, local whites. White people in particular but uhm... so that... and then obviously the whole Tshisa-nyama' thing. (Interview with Nik Rabinowitz, October 2009)

On the day of his performance at Mzoli's Meat, Nik was introduced to the audience as "South Africa's first Xhosa-speaking Jewish comedian". To the lead tunes of thunderous music, Nik came on stage, delighting the audience with recognizable

\footnotetext{
${ }^{8}$ On the comedy scene, Nik Rabinowitz is often introduced as a white multilingual speaker, who is known for his linguistic virtuosity and clever and humorous gags. Having grown up on a farm in Plumstead West, Cape Town, he was exposed early to isiXhosa as well as to Afrikaans, through socializing with farm children and speakers from the surrounding colored communities. Besides isiXhosa and Afrikaans, Rabinowitz also speaks seSotho, isiZulu, Setswana, French, German, Portuguese, and Greekalthough with limited proficiency, but illustrating the point that registers and repertoires reflect speakers' social trajectories.
} 
multilingual Cape Flats' greetings: “Awe!” (Hello in Kaapse Afrikaans), Molweni (Hello in isiXhosa), Sanibonani (Hello in isiZulu), Dumelang (Hello in SeSotho). Can I get a holla seven?!" (Hello in Tsotsitaal or Ischamto). He then proceeded to set the scene for a 'comic play of accents and voices' with a skit on multilingualism which he scenografed to take place "off-stage"-literally, after the show. At this early stage of the comic performance, two types of voices are introduced, that of a typically white speaker of English Received Pronunciation speaker, and a variety of voices of speakers of isiXhosa and black English. The speaker of normative RP is represented as wanting to project an authoritative guardianship over accents on the margins-a monolingual policing of multilingual speakers, as in lines 1-13;

Nik:

1. There's a lot of accents in the show

2. And someone recently came to me after the show

3. And said

(Imitating a white British Received Pronunciation Voice)

4. Nik

5. uh

6. we thoroughly enjoyed your show

7. thoroughly enjoyed your show

8. thoroughly

9. thoroughly

10. but we thought some of your accents

11. were somewhat condescending

12. to the, uh

13. natives

Nik easily brushes the critique aside, as he sketches a series of social encounters on the Gautrain ${ }^{9}$ where, for purposes of illustration, he demonstrates how he would address a black interlocutor first in varieties of isiXhosa and Zulu, and then in a black accented English. The purpose of the illustration is to underscore the sociopolitical importance of diversity in language, so, before picking out an audience member to initiate an interaction with around this, he makes reference to "look, it's kinda like we got 11 official languages, probably 45 unofficial ones". Nik goes on to note that if we were "having a traditional South African conversation", different accents, repertoires and registers would be included in the exchange. He imagines the conversation to go something like this:

1. Hey

2. bhuti, unjani namhlanje?

How are you today?

3. Uphilile?

\footnotetext{
${ }^{9}$ The mention of the Gautrain is significant and humorous. At the time of Nik's performance, the Gautrain project was under construction as part of the massive investment in infrastructure for the World Cup to be held in 2010. This was one of the major news events that dominated the media and the social imagination of the South African public. In particular, there was much speculation around the South African government's ability to finish a speed train (Gautrain) from Oliver Tambo International Airport (Johannesburg central) to Soweto in time, thereof the significance of Nik's humorous reference to the Gautrain just having been launched in 2020 .
} 
Are you fine?

4. Uqala qab nevinegar

I'm great/

(Imitating a Black South African speaker's voice)

5. Are you sharp, sharp

6. like vinegar

7. You have to keep the same accent

8. you stay committed

9. You change languages

10. but you keep the same accent

11. otherwise it's very confusing

12. I wouldn't say to you

13. "Bhuti, are you sharp sharp like vinegar"

(Imitating a White English Received Pronunciation voice)

In this exchange, Nik employs forms of greeting from both isiXhosa (lines 36-38), as well as a typically Iscamtho (Tsotsitaal) phrase rendered in locally accented English (lines 39-40). When delivering his English rendition of the greeting, in a Black English accent, Nik hits home his point, namely that it is far from condescending to speak to 'natives' in an accent-something that he had earlier been accused of by the white RP speaker. On the contrary, argues Nik," you change languages but you keep the same accent. Otherwise it's very confusing”. Thus, in a way similar to the rapper in the previous excerpt, Nik contrasts the linguistic voice of the 'locals' with the normative pretensions of the RP voice-the external or the foreign norm. He also does this in a framing of solidarity and consistency of relationship across local encounters-'you stay committed', thus again highlighting language as an important manifestation of associational and horizontal networks, and rejecting the imposition of a vertical norm of an extraneous norm of RP English, on a social exchange. At the same time, he appears to be profiling how the associational relationships between speakers are mutual and multilingual. Multilingual situations in accelerated conditions of mobility and contact are typically characterized by partial understandings and lack of common ground, where encounters are reconstituted as an arena for the negotiation of difference rather than the imposition of commonality (in language, speech norms, or social identity) (cf. Stroud 2001).

With his little skit here, Nik demonstrates that 'what is recognized as 'expert knowledge' of a language is not the same as being able to 'relate' through that language at a horizontal level of sociality, civility and associative structure. However, he also does something else, namely he highlights racial characteristics of speakers' voices'accents'-the social indexicalities of which cross-cut issues of multilingualism and race in complex ways, and appears to making the point that important aspects of language in multilingual South Africa have as much to do with a market of accents as they do with a market of languages.

Nik moves on to problematize even more explicitly the contest between a normative, vertical, notion of linguistic appropriateness and a more fluid and multilingual and 'polyaccentual' management of 'multilingual space' by recounting an incident when he 
worked as a game show leader on a call-in show, the "Coca-Cola Mega Millions game show". In introducing the show, he taps into the voice of a white Afrikaner (line 55);

45. And I got into a lota trouble for this at one point in my career

46. because I hosted a show on TV

47. it was called the Coca-Cola Mega Millions game show

48. Have you heard of it?

49. White people have never heard of that show

50. They only ever saw it by mistake

51. Clicking through the wrong channel (Imitating a White Afrikaner's voice)

52. "Who the hell is this Xhosa albino guy doing...?"

Clearly, the show is not one that whites watch by choice, "White people have never heard of that show" (see line 52), and that if they did come across it, it would often be by "mistake" (see line 53). The phrase "Who the hell is this Xhosa albino doing?" is a wonderfully silly construction which captures perfectly the inability of the (assumedly conservative) Afrikaner to entertain the idea that a white person is able to speak isiXhosa and perform in a black show-thereof the reference to Nik as a "Xhosa albino guy". The non-grammatical design of the utterance positions the author squarely as the uneducated Afrikaner that Nik is deliberately trying to ridicule.

Nik proceeds to recount how he got into trouble with the producer of the show on numerous occasions because of, what she perceived to be, his 'condescending tone towards the native', Thembi. He introduces the persona of Thembi by enacting the first telephone interaction he had with her when calling her form the studio. In doing so, he demonstrates a typical Xhosa opening telephone gambit, where Thembi answers her own salutation, leaving little room for the usual to and fro of introductory phatics.

Thembi:

9. $\mathrm{Hi}$

10. this is Thembi

11. how are you?

12. I'm fine thanks

In this and the rest of the narration, the mobile phone and the TV game-show setting (including the off-stage ear piece where the producer is whispering censorious commentary) provide the props, the artifacts, through which the voices and associated identities of the interlocutors are mediated and framed.

Nik:

53. $\mathrm{Hi}$

54. Ya

55. I'm also ok Thembi

56. this is Nik here

57. from the Coca Cola Mega Millions gameshow

58. and at that point she goes 
Thembi:

59. Nik?

60. Coca-Cola?

61. Yohhh!

62. Yohhh!

63. Mama

64. Sisi

65. Coca Cola

66. Yohhh!

Thembi is clearly excited by talking to Nik (lines 83-90). In order for him to accommodate her excitement, he crosses into isiXhosa and, assuming her to be a respectably aged woman, uses an appropriate honorific-in this case "Mama"-to index respect and honor, as is a common practice among isiXhosa speakers (in lines $97 \mathrm{ff}$ ).

Nik:

13. Now you only have 3 and a half minutes live

14. and you've already wasted $45 \mathrm{~s}$

15. trying to calm the woman down

16. but she's not hearing anything

17. she's so excited

18. you are like

19. Mama, uya kwazi ukudlala?

Mama, do you know how to play?

20. Do you know how the game works?

21. Do you know how to play?

Thembi:

22. Yes

23. ndiyakwazi

I know

24. ndiyakwazi

I know

25. ndiyakwazi

I know

26. yoh

(Grabs both hands and place it on his face)

67. yoh

68. ndiyakwazi

I know

As Thembi utters "Yoh", an expletive of surprise and amazement, Nik's hand touches his face in a typical embodied gesture associated with the expletive. Subsequently, he crosses back into his own voice to provide instructions about the game. Thembi must choose a number between 1 and 20 ("Uzo tshuza (please choose a) number/Uyaqala (start choosing) between 1 and 20) (see lines 108 and 109) in order to win a prize. 
Nik:

27. O'rit

28. Uzo tshuza a number

Choose a number

29. uzo qala between 1 and 20

You'll start choosing between 1 and 20

30. Choose a number between 1 and 20

31. You are going to choose your first number

32. now between 1 and $20==$

Nik's performance of the whole interaction is built around a clever juxtaposition of different speaker voices (his as commentator, that of the producer as (censorious) overhearer, Nik and Thembi as principals and authors). Throughout, the comedian slips in and out of interactions with the audience and direct interactions with Thembi. In lines $113-117$, Nik introduces a third voice into the interaction, one that in like manner to the white English-speaking accent is intent on policing Nik for his condescending use of black accents with black interlocutors,

Producer:

$113==$ Nik

114 your first warning

115 please don't use that accent

116 with the native people

117 It's very condescending

Interestingly, as the producer utters her accusation of condescension, she can be seen as reinforcing the meta-discourses of "native" language interaction previously lamented by the white English speaker accent. In order to perceive something as linguistically condescending, the utterance has to be in a language or variety that the speaker does not own or have an authentic identity in relation to, and the variety or language in question must be considered as indexical of lower social value. With her recrimination of Nik, the producer is claiming that Nik has no authentic relationship to isiXhosa (thus perhaps reinforcing a particular essentialist view of race and language) and that isiXhosa also lacks public value.

For the remainder of the interaction, the comedian performs his struggle to get Thembi to choose only numbers between 1 and 20, with Thembi proffering any number of illegitimate high value numbers in her excitement and confusion at being hosted on the Coca Cola Mega Millions Game Show. As Nik's frustration mounts, so does his use of isiXhosa and a black accent, with the producer growing increasingly censorious with every turn of the exchange. Despite her mishaps, Thembi and Nik finally succeed in getting the number right, and Thembi, much to Nik's relief and joy, wins R50ooo.

There are multiple features of interest in this extract of how language is plied into the exercise of linguistic citizenship. As with the Hip Hop performance, there is a juxtaposition of languages and accents, stylizing different voices, accompanied by a metalinguistic commentary that serves to set up an opposition between a normative and 
censorious outsider and a polycentric non-expert. And, once again, a particular vertical view of language is being challenged through forms of language that create horizontal solidarities. Importantly, the diversity of multilingual and multimodal practices opens up for new technologies of talk, and repertoires of meaning linked to alternative regimes of power.

However, perhaps most interestingly here is the introduction in Nik's discourse (also present in the raps artist's performance, although less obviously so) of the importance of accent and mode of delivery, on a par with multilingualism as an issue of 'voice'. By stylizing a range of contemporary voices in how he incorporates multiple voices, accents and racialised figures of speech into his performance at Mzoli's, Nik highlights the centrality of multilingualism and popular ideologies around language for maintaining or transforming the status quo. By performing the discursive practice of different voices, by way of accents, the comedian challenges not only longstanding meta-discourses of monolingualism (and also multilingualism), but demonstrates that linguistic transgression along many dimensions is important if we are to fully engage in agentive (multilingual) communication in township spaces.

As with the Hip Hop example, the play and contest around language practices serve simultaneously to drive home political points of a more general nature, in this case, an explicit stance on racial categorizing. Nik's performance also illustrates an overriding framing of empathy which is clearly expressed both linguistically, in the choice of language and accent when addressing Thembi, and paralinguistically, in Nik's body posture, hand movements, and verbal expletives when taking on Thembi's voice. The entanglement of multiple identities, and the relationships of power behind how these identities are assigned are also held up in Nik's performance and nicely showcased in the Afrikaner question "who the hell is this Xhosa albino guy doing?, as well as in the notion of 'condescension', a notion clearly linked to particular ideologies of authenticity and ownership of language and variety, and expert discourses on who (may) speak what. And finally, Nik's use of 'props', such as the phone, illustrates the issue of how language mediates identities through artifacts to create a particular persona. Again as we have argued by way of introduction, in the comic performance above, Nik is creating 'multivocal places' (Grasseni 2009: 37) that are both convivial and contested and appear through practices somewhat akin to gossip (Besnier 2009) where the 'setting-off of others' is a motor of alignment. The audience recognizes these practices in their production of norms of camaraderie.

\section{Discussion and conclusion}

In this paper, we have suggested that in the context of multilingual South Africa, generally, the practice of popular culture is an important resource for not only understanding multilingualism, but also for understanding how multilingualism creates the conditions for everyday convivial acts of citizenship. We took the notion of linguistic citizenship as a lens with which to study how local multilingual practices, their attendant indexicalities and their metapragmatic framing were scripted in performances in local popular spaces. Typical for both performances studied was their attention to the social production of language forms (cf. Lo and Kim 2011: 453; Magnusson and Stroud 2012) that serve to index contesting social categories such as race and gender, 
and social relations of authority, authenticity. The performances also scripted the ways in which local everyday micro-interactions and non-authoritative and marginal discourses could become resemiotized into public displays and enactments of citizenship, linking the parochial realm of comedy with that of the wider community through audience engagement.

A general finding here is how multilingualism is represented and practiced transgressively as manifested in elements highly indexical of criminal, marginal and socially stigmatized identities, in the case of the rapper, and in contempt for the use of African languages or accents, in the case of Nik. The heteroglossic features and polysystemic forms of expression that speakers deploy are used to counter the censorious and authoritative voices that seek to constrain the practice of multilingualism in public spaces which is presented as defined by monolingualism and monoglot linguistic policing (Androutsopoulos 2009).

Secondly, both performances typically display a multilingualism of entanglementwhere the rapper and the comedian embody in one and the same voice, the multiple voices (imagined to be) found in the local context. In the rapper's case, this is apparent in the foreigner's expression of confused amazement as to "who is this person?", who seems to embody all voices of the township. Nik's performance in particular emphasizes an interesting form of entanglement, that is, an entanglement of cultures, histories, languages, spaces-realized in paralinguistic imitations of the isiXhosa body and reflecting a particular mode of corporeal generosity (Diprose 2002). This is underscored by the way Nik makes the Afrikaner question: "who the hell is this Xhosa albino guy?" Rather than a conventionally understood multilingualism of compartmentalization stuck to strand-based identities, we find a performance of multiple voices that transcend that separation.

A third feature of multilingualism from the perspective of linguistic citizenship is how multilingual encounters (negotiations of diversity, inclusion and exclusion) are depicted through interpersonal exchanges of a fairly mundane type (e.g. greetings) that take place in the everyday, local grassroots context. It is surely significant that it is the trope of the encounter that frames multilingual entanglements in the South African context, clearly pointing to the salience of the 'collision' of strand-based identities. The meaning conveyed by the comedian and the rapper is that despite the ubiquity of globalization and concomitant translocal scaling of multilingualism, the local-through the encounter-is crucial to understanding the play of linguistic agency and voice on the margins. In both cases, the importance of the local was offset against a transgressive reflection on norms of English and the confused foreigner/outsider; the monoglot and stratified idea of language they were styled as holding came up short when in contact with the local realities.

A fourth feature of both performances is the importance of non-expertness, even antiexpertness. Languages are scripted as transgressing against norm or standard forms of use, and as raising eyebrows amongst monolingual and monoglot figures of authority. It is the practice of crossing boundaries, either linguistically or otherwise, that is presented as 'inexpert', probably on the basis that it violates essentialist identities and senses of 
authenticity and skill (e.g. nativeness) linked to 'real' identities. Inexpertness is surely also a component of the condescending attitude that Nik allows himself to be accused of. However, at the same time, in-expertness is what opens up horizontal networks of communication, as well as transgression against a normative order and the emphasis on the local. The performance critically also highlights how a normative stance that recognizes only particular ways of speaking as legitimate, owned and authentic, may be used to establish categories such as 'the native' in ways that ultimately discourages conviviality.

A fifth feature that is shared by both performances is the way language is used to link the human to the not-so-human. The stylization of voice in the rap performance fundamentally created and stood proxy for township space, and a linguistic landscape that animated and gave symbolic significance to those who inhabited it (and vice versa). Likewise, in Nik's case, the telephone and the TV are important props that allow particular aspects of the actors' identities and roles and voices (e.g. animator, overhearer etc.) to be mediated and performed. In both cases, the non-human world of landscapes and technologies are part of the human assemblage, as "lives are not just acting out internal scripts: they are material enfoldings of complex topologies of living and non-living entities" (Hinchliffe and Whatmore 2006: 128).

Any political philosophy of language will reflect prevailing ideas of citizenship. The prominence of nation-state discourses of citizenship finds resonance in much contemporary language planning and policy discourses formulated in terms of conventional notions of language and a Habermasian understanding of a consensual, rational and official public sphere. Critics of contemporary, modernist traditions of language policy have argued for conceptual shifts away from the notion of policy to that of 'normativity', 'policing' and 'practice'. Concurrently, they argue for a shift away from an idea of multilingualism as 'parallel or multiple monolingualisms' to a notion of 'heteroglossia with an increased emphasis on "voice" (Blommaert et al. 2009: 204; cf. also Ricento 2006; Shohamy 2006) that highlights the importance of fragmentation, hybridization and destabilized identities. Importantly, they suggest replacing a hegemonic view of the nation-state and main actor to polycentric multilingual environments, and an understanding of "language policy as an evolving phenomenon shaped and reshaped by discursive practices which in turn are embedded in the multiple contextual and semiotic resources available in specific social activities and environments” (Blommaert et.al 2009: 207).

Linguistic citizenship focuses on the semiotic means whereby speakers enact participation and community in mundane, everyday spaces. We suggest that it offers alternative possibilities for understanding voice and agency on interlinked public arenas (cf. Lofland 1998), and this is very much in line with other critiques of modernist language policy (cf. McCarty 2011; Hornberger and Johnson 2011). McCarty (2011: xii), for instance, argues that "[Language] Policy is not a disembodied thing, but rather a situated cultural process-the complex practices, ideologies, attitudes, and formal and informal mechanisms that influence people's language choices in profound and pervasive everyday ways". Similarly, Hornberger and Johnson (2011: 282) argues that ethnographic research on language policy uncovers "indistinct 
voices, covert motivations, embedded ideologies, invisible instances, or unintended consequences" in the way we approach and generally understand language, agency and voice. Our study of the two performances has shown how practices of linguistic transgression and the entanglement of multiple voices are key features of local enactments of citizenship. These transgressing and entangled voices, with their associated indexicalities, are found embedded in multi-semiotic contexts and media. Linguistic citizenship encourages research into the implications of non-standardness and non-fixedness for acts of citizenship,-where language is policed by its users/speakers ('non-experts') and subject to multiple, polycentric normativities.

Built into the emphasis on practices in linguistic citizenship is the recognition that semiotic forms other than language contribute to the emergence of agency and voice at local points of production. Much meaning is entextualized, resemiotized and transposed across chains of (material and symbolic) artefacts. Thus, linguistic citizenship is an attempt to shift the brief of a politics of language towards a focus on language as part of a broader, socially distributed semiotics-also including, for example, a posthumanist interest in materialities of signage (Stroud and Jegels 2012, ftc.).

More generally, the prevalence of multiple normativities and polycentric local practices, where the momentary and uncertain is the 'norm', put the lie to a policy reliant on discourses of linguistic artefactualisation and an idea of the temporal fixity of language. Rather, policy needs to engage with the momentary and fluid transport of a variety of linguistic forms across different semiotic and material artefacts, and with the different discursive and material framings of linguistic forms cf. Androutsopoulos 2009: 288). This in turn means that policy discourses need to move away from statements of facts to engagements with possibilities, shifting the "status and form of expertise" (Hinchliffe and Whatmore 2006: 131) from experts to grassroots-to those who 'live inexpertly'. Finally, rather than attention to scaled linguistic productions, focus should be on new forms of horizontal linguistic communion, that is, away from the 'given' (the recognized linguistic system) in favor of linguistic practice and improvisation, and to how messages circulate in everyday, informal networks (Stroud 2001).

\section{Acknowledgments}

We would like to thank the Vlaamse Interuniversiteitse Raad (VLIR) and the SANPAD'S Community Development through Early Literacy project for providing the funding for the research of this paper. Also, thanks to the Max Planck for Religious and Ethnic diversity in the authoring of this work. 


\section{References}

Agha, A. (2003). The social life of cultural value. Language \& Communication, 23(3), 231-273. Agninotri, R. K. (2007). Towards a pedagogical paradigm rooted in multilinguality. International Multilingual Research Journal, 1(2), 79-88.

Amin A. (2002). Ethncity and the multicultural city. Environment and Planning A, 34, 959-980.

Androutsopoulos, J. (2009). Policing practices in heteroglossic mediascapes: A commentary on interfaces. Language Policy, 8(3), 285-290.

Arnfred, S., \& Utas, M. (Eds). (2007). Re-thinking Africa: A contribution to the Swedish Government White Paper on Africa. Nordic Africa Institute: Uppsala. (http://www.nai.uu.se/about/africa_strategies2/rethinkikng_africa).

Ashby, W. (2004). Unmasking narrative: A semiotic perspective on the Conviviality/Non-Conviviality Dichotomy in Storytelling about German "Other". Trans: Internet-Zeitschrift fü $r$ Kulturwissens- chaften, 15, 1-9.

Besnier, N. (2009). Gossip and the everyday production of politics. Honolulu: University of Hawai'i Press.

Blommaert, J. (forthcoming). Chronicles of Complexity: ethnography, superdiversity and linguistic landscapes. Clevedon: Multilingual Matters.

Blommaert, J., Kelly-Holmes, H., Lane, P., Leppæ̈ nen, S., Moriarty, M., Pietikä inen, S. (2009). Media, multilingualism and language policing: An introduction. Language Policy, 8, 203-207.

Chipkin, I. (2007). Does South Africans exist? Nationalism, democracy and the identity of the people. Johannesburg: Wits University Press.

Coste, D., \& Simon, D-L. (2009). The plurilingual social actor: language, citizenship and education. International Journal of Multilingualism, 6(2), 147-161. Diprose, R. (2002). Corporeal Generosity Albany. NY: Suny.

Dolby, N. (2006). Popular culture and public space: The possibilities of cultural citizenship. African Studies Review, 49(3), 31-47.

Fanshawe, S., \& Sriskandarajah, D. (2010). 'You can't put me in a box: Super-diversity and the end of identity politics in Britain. Institute for Public Policy Research.

Gilroy, P. (2004). After empire: Melancholia or convivial culture. London: Routledge.

Goebel, Z. (2010). Language, migration, and identity: Neighborhood talk in Indonesia. New York: Cambridge University Press.

Grasseni, C. (2009). Developing skill, developing vision. New York: Berghahn.

Hammett, D., \& Jayawardane, N. (2009). Performing the primitive in the postcolony: Nyoni's Kraal in Cape Town. Urban Forum, 2O, 215-233.

Harrington, L., \& Bielby, D. (Eds.). (2001). Popular culture: Production and consumption. Massachusetts: Blackwell Publishers.

Higgens, C. (2009). From da Bomb to Bomba: Global Hip-Hop Nation. In H. S. Alim, A. Ibrahim \& A. Pennycook (Eds.), Global linguistic flows: hip-hop cultures, youth identities, and the politics of language (pp. 95-112). London: Routledge.

Hinchliffe, S., \& Whatmore, S. (2006). Living cities: Towards a politics of conviviality. Science as Culture, 15(2), 123-138.

Hornberger, N. H., \& Johnson, D. C. (2011). The ethnography of language policy. In T. L. McCarty (Ed.), Ethnography and language policy (pp. 273-289). London: Routledge. 
Iedema, R. A. (2001). Resemiotization. Semiotica: journal of the international association for semiotic studies, 137(1/4):23-39.

Illich, I. (1973). Tools for conviviality. New York: Harper and Row Publishers.

Karner, C., \& Parker, D. (2011). Conviviality and conflict: Pluralism, resilience and hope in inner-city Birmingham. Journal of Ethnic and Migration Studies, 37(3), 355372.

Kennett, P. (2008). Governance, Globalization and Public Policy. Cheltenham, UK: Edward Elgar.

Kerfoot, C. (under review). Making and shaping participatory spaces: Resemiotization and citizenship agency. In L. Lim, C. Stroud, \& L. Wee (Eds.), The Multilingual Citizen: towards a politics of language for agency and change. Clevedon: Multilingual Matters.

Kriger, R., \& Zegeye, A. (Eds.). (2001). Culture in the new South Africa. Cape Town: Kwela Books. Lo, A., \& Kim, J. C. (2011). Manufacturing citizenship: Metapragmatic framings of language competencies in media images of mixed race men in South Korea. Discourse \& Society, 22, 440-457.

Lo, A., \& Kim, J. C. (2012). Linguistic competency and citizenship: Contrasting portraits of multilingualism in the South Korean public media. Journal of Sociolinguistics, 16(2), 255-276. Lofland, L. H. (1998). The public realm: Exploring the city's quintessential social territory. Hawthorne, NY: Aldine de Gruyter.

Magnusson, J. E., \& Stroud, C. (2012). High proficiency in markets of performance - a sociocultural approach to nativelikeness. Studies in second language acquisition, 34(02), 321-345.

McCarty, T. L. (Ed.). (2011). Ethnography and language policy. London: Routledge.

Mercado, S. (2008). Linguistic citizenship: Language policy, social cohesion and immigration in Barcelona, Spain. Unpublished Phd thesis. Berkeley: University of California.

Moriarty, M., \& Pietikä inen, S. (2011). Micro-level language-planning and grass-root initiatives: A case study of Irish language comedy and Inari Sá mi rap. Current Issues in Language Planning, 12(3), 363-379.

Mouffe, C. (2000). Deliberative democracy or Agonistic pluralism (pp. 1-17). Institute for Advanced Studies, Vienna: Political Science Series 72.

Nayak, A. (2010). Race, affect and emotion: Young people, racism, and graffiti in the postcolonial English suburbs. Environment and Planning A, 42(10), 2370-2392.

Newell, S. (2009). Enregistering modernity, bluffing criminality: How Nouchi speech reinvented (and Fractured) the nation. Linguistic Anthropology, 19(2), 157-184.

Noble G. (2009). Everyday cosmopolitanism and the labour of intercultural community. In A. Wise \& S. Velayutham (Eds.), Everyday multiculturalism (pp. 47-67). Basingstoke: Palgrave Macmillan. Nuttall, S., \& Michael, C.-A. (Eds.). (2000). Senses of culture: South African culture studies. Oxford: Oxford University Press.

Osborne, T., \& Rose, N. (1999). Governing cities: Notes on the spatialisation of virtue. Environment and Planning D: Society \& Space, 17, 737-760.

Pennycook, A. (2007). Global Englishes and transcultural flows. London: Routledge. Prophets of Da City. (1995). Universal Soulijaz. South Africa: Ghetto Ruff Records. 
Rampton, B. (2006). Language in Late Modernity: Interaction in an urban school. New York: Cambridge University Press.

Ricento, T. (Ed.). (2006). Ideology, politics, and language politics: Focus on English. Amsterdam: John Benjamins.

Rogerson, C. M. (1988). "Shisha Nyama": The rise and fall of the native eating house trade in Johannesburg. Social Dynamics, 14(1), 20-33.

Rose, N. (2000). Governing cities, governing citizens. In E. Isin (Ed.), Democracy, Citizenship and the Global City (pp. 95-109). London: Routledge.

Roth-Gordon, J. (2009). The language that came down the hill: Slang, crime, and citizenship in Rio de Janeiro. American Anthropologist, 111(1), 57-68.

Sennett, R. (1974). The fall of public man. New York: Norton. Sennett, R. (2005). Civility. Urban Age, Bulletin, 1, 1-3.

Shohamy, E. (2006). Language policy: Hidden agendas and new approaches. London: Routledge. Simone, A. M. (2008). Some reflections on making popular culture in Urban Africa. African Studies Review, 51, 75-89.

Stroud, C. (2001). African mother tongue programs and the politics of language: Linguistic citizenship versus linguistic human rights. Journal of Multilingual and Multicultural Development, 22(4), 339-355.

Stroud, C. (2009). Towards a postliberal critique of language rights: towards a politics of language for a linguistics of contact. In J. Petrovic (Ed.), International perspectives on bilingual education: Policy, practice and controversy (pp. 191218). New York: Information Age Publishing.

Stroud, C., \& Heugh, K. (2004). Linguistic human rights and linguistic citizenship. In D. Patrick \& J. Freeland (Eds.). Language rights and language survival: $A$ sociolinguistic exploration (pp. 191-218). Manchester: St Jerome.

Stroud, C., \& Jegels, D. (2012). Semiotic landscapes and mobile narrations of place: Performing the local. International Journal of the Sociology of Language (In Print).

Taylor, M. (2004). Oh no it isn't: Audience Participation and Community Identity. Trans: Internet- Zeitschrift für Kulturwissenschaften, 15, 1-8.

Wardrop, J. (2006). Private cooking, public eating: Women street vendors in South Durban. Gender, Place and Culture, 13(6), 677-683.

Wasserman, H., \& Jacobs, S. (Eds.). (2003). Shifting selves: Post-apartheid essays on mass media, culture, and identity. Cape Town: Kwela Books.

Werbner, P. (1999). Global pathways: Working class cosmopolitans and the creation of transnational ethnic worlds. Social Anthropology/Anthropologie Sociale, 7, 17-35.

Wessendorf, S. (2010). Commonplace diversity: Social interactions in a super-diverse context. MMG working paper, pp 10-11.

Williams, Q., \& Stroud, C. (2010). Performing rap Ciphas in late-modern Cape town: Extreme locality and multilingual citizenship. Afrika Focus, 23(2), 39-59.

Wood, P., \& Landry, C. (2007). The intercultural city: Planning for diversity advantage. London: Sterling: Earthscan.

Yuval-Davis, N. (1999). What is 'transversal politics'? Soundings 12, 94-98. 


\section{Author Biographies}

Quentin Emmanuel Williams is currently a Sociolinguistics of Superdiversity Research Fellow and forms part of a team of linguistic ethnographers conducting research on multilingualism, mobility and superdiversity in a busy CBD area. He recently completed his doctorate entitled, Multilingualism in latemodern Cape Town: a focus on popular spaces of Hip-Hop and Tshisa-Nyama. He has published papers on the performance of multilingualism, Hip- Hop and Tshisa-Nyama cultures and multilingual citizenship in urban Cape Town. He was formerly a part time lecturer in the Linguistic Department at the University of the Western Cape.

Christopher Stroud is a Senior Professor at the University of the Western Cape and Professor of Bilingual Research at Stockholm University. He has researched and written widely on multilingualism, language planning and policy and language education in contexts as diverse as Papua New Guinea, South East Asia, Scandinavia and Southern Africa. He is currently working on elaborating the idea of linguistic citizenship Multilingualism in transformative spaces: contact and conviviality 